\title{
REPRODUCCIÓN ASISTIDA Y DETERMINACIÓN DE LA FILIACIÓN
}

\author{
Roncesvalles BARBER CÁRCAMO \\ PROFESORA TITULAR DE DERECHO DERECHO CIVIL \\ UNIVERSIDAD DE LA RIOJA, LA RIOJA.
}

SUMARIO: I. Previo. II. Títulos de determinación y clases de filiación. III. La determinación de la filiación en la reproducción humana asistida: I. El principio inspirador. 2. La determinación de la maternidad. 3. La determinación de la paternidad.- IV. Los interrogantes abiertos por la LTRHA: I. La impugnación de la paternidad del padre no casado que consiente. 2. La posibilidad de elegir al padre, que no al donante. 3. La situación jurídica del donante. V. Conclusión: valoración de la Ley I4/2006, de 26 de mayo, de Técnicas de Reproducción Humana Asistida.

RESUMEN: La determinación de la filiación de los nacidos mediante técnicas de reproducción humana asistida responde a reglas especiales, contenidas en la Ley sobre la materia, que excepcionan el régimen del Código civil. Tales sustanciales diferencias muestran la diferente filosofía que subyace a dichas normas: la LTRHA prioriza la voluntad del progenitor y el Código, el principio de verdad biológica. Pese a ello, la LTRHA se remite al Código para integrar sus numerosas lagunas legales, lo cual plantea difíciles problemas de aplicación e interpretación jurídica. Este trabajo ofrece una aproximación crítica a dicha Ley, y algunas soluciones.

PALABRAS CLAVE: Filiación- Determinación- Fecundación Asistida.

ABSTRACT: The determination of the parentage of children born through medically assisted procreation techniques in Spain responds to special rules contained in the Act on the matter, which are different from Spanish civil Code regime. Such substantial differences show the opposite philosophy behind those rules: the LTRHA is inspired on parent's intention, and the Code, on the principle of biological truth. Nevertheless, LTRHA refers to the Code to integrate its many loopholes, which raises difficult issues of application and legal interpretation. This paper provides a critical approach to the Act, and some solutions.

KEYWORDS: Affiliation- Parenthood- Determination- Medically assisted procreation.

\section{Previo}

Las cuestiones jurídicas contenidas en una Ley de Técnicas de Reproducción Humana Asistida son numerosas, variadas y de sustancial calado, al afectar a temas no sólo íntimos y personales, sino cargados de implicaciones filosóficas. Sin ánimo exhaustivo: la capacidad reproductiva, de la mano del supuesto derecho a la reproducción; las relaciones de filiación, en su contenido, fundamento y determinación; el ámbito de la autonomía de la voluntad y sus límites, latente en los consentimientos requeridos para la aplicación de las técnicas y sus consecuencias, y en suma, cuantos plantea la intervención legislativa sobre el origen de la vida y, en general, sobre la investigación científica. La radical trascendencia de cada uno de ellos justifica la atención que la doctrina jurídica ha dispensado a nuestra 
vigente Ley I4/2006, de 26 de mayo, sobre Técnicas de Reproducción Humana Asistida, así como a sus precedentes.

Como objeto de su análisis, este trabajo se centra en la determinación de la filiación nacida a través de las técnicas de reproducción humana asistida. Es un tema crucial para el Derecho, en cuanto dirigido a la identificación de las partes de la relación de filiación, con todos sus efectos jurídicos. Se muestra, además, sumamente complejo, por la pluralidad de intereses en posible conflicto a atender. En su regulación, la Ley de Técnicas de Reproducción Humana Asistida ha alterado sustancialmente las premisas sobre las que el Código civil construyó el Derecho de filiación en la Ley II/I98I, de I3 de mayo, según queda patente en decisiones tan llamativas como la de posibilitar la doble maternidad biológica, sin padre (art. 7.3 LTRHA). Ello obliga a revisar afirmaciones tan básicas o de partida como la de que la determinación de la filiación persigue la identificación del padre y de la madre de una persona. Como decía, tal decisión legislativa puede ser la más llamativa, pero en absoluto es la única discutible, ya no sólo desde consideraciones filosóficas, sino de mera técnica jurídica. Porque la Ley 14/2006, de 26 de mayo, sobre Técnicas de Reproducción Humana Asistida, plantea más problemas que los que resuelve, según se expondrá seguidamente.

\section{Títulos de determinación y clases de filiación}

En general, para determinar la relación jurídica de filiación y establecer así el conjunto de efectos que comporta (patria potestad, obligaciones de vela y custodia, alimentos, apellidos, derechos sucesorios), el Derecho elige unos concretos hechos y actos a los que atribuye tal función. De ahí su nombre de títulos de determinación de la filiación, en cuanto sirven para establecerla. Estos títulos vienen a responder a la pregunta: « ¿quién debe ser el padre/madre de un niño?». Pregunta que incorpora dos premisas obvias: una, la relación biológica de filiación y la jurídica son distintas, por lo que no siempre coinciden; y dos, ante el dato anterior, el Derecho debe decidir cómo articula tal disparidad, si en términos de excepción o de normalidad. En otras palabras el legislador debe decidir entre un sistema jurídico de filiación que tienda a la coincidencia entre la realidad fáctica y la

' La bibliografía al respecto es muy abundante. Entre otros, pueden consultarse: AA. VV., La filiación a finales del siglo XX. Problemática planteada por los avances científicos en materia de reproducción humana, Madrid, Trivium, I988; AlKorTA IdiÁQuez, «Nuevos límites del derecho a procrear», Derecho Privado $y$ Constitución, nº 20, 2006, pp. 9-6r; BERCOVITZ RodRíQUEZ-CANO, «Reproducción asistida post mortem», Aranzadi Civil, 200I.2, pp. 21652I67; CовACHo Gómez (dir.), Comentarios a la Ley 14/2006, de 26 de mayo, sobre Técnicas de Reproducción Humana Asistida, Cizur Menor, Thomson-Aranzadi, 2007; De Verda y BEAMONTE, «Libertad de procreación y libertad de investigación (algunas reflexiones a propósito de las recientes leyes francesa e italiana sobre reproducción asistida)», La Ley, 2005, tomo I, pp. I5IO-I523; DíAZ MARTíNEZ, «La doble maternidad legal derivada de la utilización de técnicas de reproducción humana asistida», Derecho Privado y Constitución, $\mathrm{n}^{\circ}$ 2I, 2007, pp. 75-I29; GARRIGA GORINA, «El conocimiento de los orígenes genéticos en la filiación por reproducción asistida con gametos donados por un tercero», Derecho Privado y Constitución, nº 21, 2007, pp. I67-228; LLEDÓ YAGÜE (dir.), Comentarios científico-jurídicos a la Ley sobre técnicas de reproducción humana asistida, Madrid, Dykinson, 2007; MAGALDI, Derecho a saber, filiación biológica y Administración Pública, Madrid, Marcial Pons, 2004; MARTínEZ DE AGUiRRe AldAZ, «Problemas jurídicos derivados del consentimiento en las técnicas de reproducción asistida», en El juez civil ante la investigación biomédica, Cuadernos de Derecho Judicial, X-2004, Madrid, Consejo General del Poder Judicial, pp. 249-302; NANClARES VALLE, «Las técnicas de reproducción asistida en España: aspectos problemáticos de la Ley de 26 de mayo de 2006 n.I4, con relación a la Ley italiana de I9 de febrero de 2004 n. 40», Il Diritto di Famiglia e delle Persone, 2007.2, pp. 846-90I; NANCLARES VALLE, «Reproducción asistida y doble maternidad por naturaleza», Aranzadi Civil, 2008.I, pp. 2243-2270; NiETO Alonso, «Reproducción asistida y anonimato de los progenitores», Aranzadi Civil, 2004.3, pp. 2309-2336; PANTALEÓN PRIETO, «Contra la ley de técnicas de reproducción asistida», en Homenaje a Juan Roca Juan, Universidad de Murcia, I989, pp. 64I-670; PÉREZ MONGE, La filiación derivada de técnicas de reproducción asistida, Madrid, Colegio de Registradores, 2002; QUESADA GONZÁLEZ, «El derecho (¿constitucional?) a conocer el propio origen biológico»,A.D.C., I994, II, pp. 237-303; RIVERO HERnÁNDEZ, «La constitucionalidad del anonimato del donante de gametos y el derecho de la persona al conocimiento de su origen biológico» (de la STC iı6/ı999, de I7 de junio, al affaire Odièvre, Revista Jurídica de Cataluña, 2004.I, pp. I05-I34. 
jurídica, y otro que asuma, por razones diversas, la separación entre ambas. En esta elección, lógicamente, el legislador no tiene una plena libertad de configuración normativa, sino que se encuentra limitado por las previsiones constitucionales al efecto.

En concreto, la Constitución española de 1978 contiene las siguientes normas con incidencia sobre el régimen de la filiación:

a) El principio de no discriminación por razón de nacimiento: art. I4 CE (esto es, la igualdad en el tratamiento jurídico de los hijos con independencia del origen matrimonial o extramatrimonial de su nacimiento). $\mathrm{CE})$.

b) La protección de la familia, obligación de todos los poderes públicos (art. 39.I

c) La protección de los hijos y de las madres con independencia de su estado civil (art. 39.2 CE).

d) La investigación de la paternidad, recogida inmediatamente después de la obligación anterior, y al servicio de la primera (art. 39.2 CE). La recepción constitucional de la obligación legislativa de «posibilitar» la investigación de la paternidad supuso la abolición de una barricada histórica de defensa del varón frente a la asunción de la propia responsabilidad como progenitor, que los Códigos civiles del siglo XIX habían recibido del de Napoleón como prohibición de dicha investigación.

Estas exigencias constitucionales eran incompatibles con el régimen de filiación vigente al aprobarse la Constitución, prácticamente inalterado desde la redacción original del Código civil, por lo que provocaron su reforma, por Ley II/I98I, de I3 de mayo. Esta reforma abordó la filiación por naturaleza, esto es, la que une a personas que descienden unas de otras. Desde la aplicación de los principios constitucionales mencionados, opta por un sistema de determinación de la filiación basado en la verdad biológica, en cuya virtud se favorece que quien es padre biológico, sea tenido por padre legal, lo cual comporta importantes efectos sobre el régimen de acciones de filiación.

Por su parte, la adecuación de la filiación adoptiva a los principios constitucionales se llevó a cabo por Ley 2I/I987, de in de noviembre, que establece la total equiparación de efectos entre esta clase de filiación y la biológica o natural. Obviamente, en la filiación adoptiva se asume la falta de relación biológica entre los padres e hijos legales, para dotar a los menores del mejor recurso posible en orden a su protección. La constitución de la filiación adoptiva es judicial: requiere de una resolución judicial en la que se constate el cumplimiento de todos los requisitos legales y la mayor adecuación de los padres adoptantes al interés del adoptando.

Y bien: ¿qué sucede con la reproducción asistida? Un legislador apresurado puede partir de la siguiente premisa: la filiación nacida tras el sometimiento de los progenitores a técnicas de reproducción humana asistida es indudablemente filiación natural, porque la manipulación del hijo en sus orígenes en nada debe alterar la clasificación jurídica de la filiación. Por ello, el régimen de su determinación debe reconducirse al de la filiación natural. Esa fue la decisión tomada por el legislador en la primera Ley española de Reproducción Humana Asistida, la Ley 35/1988, de 22 de noviembre, y se mantiene en la vigente Ley I4/2006, de 26 de mayo. Sin embargo, la mayoría aplastante de la doctrina y la propia realidad viene demostrando la insuficiencia e inadecuación de tal decisión.

Efectivamente, el art. 7.I LTRHA, bajo el título «Filiación de los hijos nacidos con las técnicas de reproducción asistida», reconduce su regulación a «las Leyes civiles, a salvo de las especificaciones establecidas en los tres siguientes artículos» (arts. 8, 9 y io LTRHA). 
El plural, claramente, debe ponerse en relación con la competencia autonómica en materia civil: la regulación española sobre filiación no sólo se contempla en el Código civil, sino también en otras leyes civiles autonómicas. En concreto, Cataluña (art. 235 de la Ley 25/20ıo, de 29 julio, del Libro Segundo del Código Civil de Cataluña, y antes arts. 87 a II4 C.F.C.) y Navarra (leyes 68 a 72 F.N.N.) tienen su propia regulación en materia de determinación de la filiación.

Por tanto, en virtud de esta regla hemos de entender aplicable el régimen del Código sobre determinación de la filiación por naturaleza, que sólo queda desplazado por la existencia de norma especial en los tres artículos siguientes. La aplicación del Código civil no es subsidiaria, sino directa, y sólo queda desplazada en presencia de norma concreta contenida en esta Ley especial. El legislador ha renunciado a establecer una tercera clase de filiación, a sumar a la natural y la adoptiva, o a discriminar según el tipo de reproducción asistida empleada, opciones defendidas por parte de la doctrina ${ }^{2}$ : simplemente, se ha limitado a establecer unas normas especiales a integrar con el régimen general de la filiación natural.

Tras la reforma operada en la LTRHA por la Ley 3/2007, de I5 de marzo, de rectificación registral del sexo, lo previsto por el mencionado art. 7.I debe corregirse incluso en cuanto a su literalidad, dado que ésta incluyó, como párrafo 3 del propio art. 7, una regla ya no especial, ni siquiera excepcional, sino totalmente estrambótica para el Derecho vigente de filiación: la posibilidad de que sean tenidas, como madres de un hijo, dos mujeres casadas entre sí. Es difícil entender por qué esta regla -que luego criticaré en cuanto a su contenido sustantivo-, no se incluyó en su sede correcta, el art. 8 de la Ley (Determinación legal de la filiación): la chapucería de la Ley parece no encontrar ni siquiera límites formales o sistemáticos. Porque una aplicación literal del art. 7.I conduciría a la inaplicación del art. 7.3.

Así pues, para determinar la filiación, la LTRHA se remite a la aplicación directa del Código civil, cuyo sistema está basado desde I98I en la verdad biológica, a salvo las especificaciones que aquélla contempla. El punto de partida no puede ser más sorprendente, dado que la LTRHA española admite la fecundación con semen de donante anónimo, la donación igualmente anónima de óvulos e incluso de pre-embriones, y dicho anonimato se eleva en la Ley a la categoría de dogma (art. 5.5), de modo que la revelación de la identidad de los donantes de gametos es excepcional. Sólo en circunstancias extraordinarias que comporten un peligro cierto para la vida o la salud del hijo podrá revelarse dicha identidad, siempre y cuando, además, esta revelación sea indispensable para evitar el peligro (art. 5.5.3 LTRHA). Por consiguiente, el lugar que para el Código ocupa la verdad biológica, y la tendencia a que sea padre legal el genético, en la LTRHA lo sustituye la voluntad de quien desea ser progenitor, con independencia del origen genético del material reproductor empleado. A priori, ambas regulaciones parecen difícilmente conciliables, aunque el Tribunal Constitucional, en la STC iı6/1999, de I7 de junio, al declarar constitucional dicho anonimato, encontró una vía para su conciliación, fundada en las reglas especiales de los artículos 8 a io LTRHA, que paso a exponer.

\footnotetext{
${ }^{2}$ Vid. Verdera Server, «Comentario a los artículos 7 y 8», en Comentarios a la Ley 14/2006, de 26 de mayo, sobre Técnicas de Reproducción Humana Asistida, dir. СовACHO GómEZ, Cizur Menor, Thomson-Aranzadi, 2007, pp. 2I7-2I9.
} 


\section{La determinación de la filiación en la reproducción humana asistida}

\section{III.1 El principio inspirador}

La filosofía de la Ley, y con ello comparte el criterio habitual del Derecho comparado, es que la voluntad de generar un nuevo ser humano a través de la aplicación de estas técnicas sustituye al dato biológico, convirtiendo en padre o madre legal a quien presta su consentimiento para aquéllas ${ }^{3}$. Ahora bien, el legislador español no reviste a dicha voluntad del carácter de título de determinación de la filiación, a sumar a los presentes en el Código civil (arts. II5 y I20): siguen aplicándose éstos, introduciendo dicho consentimiento sólo modulaciones en sus efectos. Con una salvedad: la manifestación de la mujer casada con otra ante el Encargado del Registro Civil, y previa al nacimiento del hijo de su cónyuge, incorporada en el art. 7.3 LTRHA. Esta previsión legal no puede entenderse sino como un nuevo título de determinación de la filiación, ligado a la voluntad pero esencialmente distinto al reconocimiento.

Veamos seguidamente cómo concreta el legislador este principio inspirador, en función de la maternidad o paternidad, y del carácter matrimonial o extramatrimonial de la filiación. Tal es el contenido de los artículos 7 a io LTRHA.

\section{III.2 La determinación de la maternidad}

Hasta su reforma de marzo de 2007 , la LTRA descartó cualquier otro título de determinación materna diferente al parto, lo cual se recoge con ocasión de la regulación de la gestación por sustitución (art. Io): podría decirse que es el último bastión del mater semper certa est. En su virtud, el origen del material biológico (gametos o preembriones) es irrelevante para el Derecho, al menos para la determinación de la maternidad: es madre quien pare, como complemento a la nulidad de todo contrato de maternidad subrogada ${ }^{4}$. El parto constituye un límite infranqueable a la autonomía de la voluntad, tan potenciada en otros ámbitos por esta Ley: el legislador ha optado por la biología del nacimiento, y no por la de la concepción 5 .

Ahora bien, sólo para una de las madres. La regla expuesta procede de la Ley de I9 88 y permanece literalmente inalterada en la vigente de 2006 , pero la ya mencionada adición del art. 7.3 en 2007 , por la Ley de rectificación de sexo, ha establecido exactamente el criterio contrario para la cónyuge de la madre que da a luz. Porque aquélla, por su sola manifestación de voluntad de ser tenida como madre, ante el Encargado del Registro Civil y

\footnotetext{
${ }^{3}$ Esta introducción de la voluntad como criterio determinante para la atribución de la filiación es excepcional en nuestro sistema, y no cabe su aplicación analógica cuando entre los progenitores media relación sexual. Por ello afirmo en el texto que el consentimiento a la práctica de técnicas de reproducción asistida se equipara al dato biológico: mediando relación sexual, la existencia o no de consentimiento para la fecundación es irrelevante. Vid. en este sentido la SAP Palencia (Sección I') 20 enero 2008 (JUR 2008\3I8329), que desestima la oposición del varón a la acción de reclamación de la filiación con semejante fundamento.

${ }^{4}$ Pese a la nulidad de dicho contrato, la RDGR de I8 febrero 2009 (RJ 2009\I735) ha admitido la inscripción de la filiación matrimonial de un hijo logrado por un matrimonio español homosexual de hombres, a través de un vientre de alquiler, en California. La Resolución se encuentra pendiente de un recurso presentado por el Fiscal.

5 Lo cual no deja de encontrar críticas en la doctrina, que señala desde diferentes planteamientos la incongruencia de la rigidez legislativa en este punto, en evidente contraste con la general preponderancia de la voluntad en la Ley y la tendencia a la verdad biológica presente en nuestro sistema de filiación. Tras la que algunos autores, incluso, sólo ven razones económicas, y en ningún caso de protección del hijo: vid. VERDERA SERVER, loc. cit., pp. 260 ss., donde refleja el debate doctrinal al respecto.
} 
antes del nacimiento del hijo ${ }^{6}$, es tenida como madre legal. Lo cual es contrario, no sólo al expuesto ligamen de la maternidad con el parto, sino al valor atribuido al consentimiento, en general, en la propia LTRHA, que para producir efectos sobre la filiación debe referirse a la práctica de una concreta técnica de reproducción asistida. Por no mencionar la contradicción con la verdad biológica, principio rector de la regulación del Código. En realidad, la introducción en nuestro Derecho de la doble maternidad por naturaleza, contraria a su unidad natural y a toda la regulación del Código sobre la filiación (como muestra, un botón: art. II3.2 Cc) ${ }^{7}$, es tan artificial y difícil de encajar en nuestro sistema, por ajena a cualquiera de sus principios, que no resiste el mínimo análisis de técnica jurídica. Según ha podido comprobar la propia Dirección General de los Registros y del Notariado, que en su resolución $\left(4^{\mathrm{a}}\right)$ de I4 de octubre de 2009 , tras referirse a dicha manifestación como «el derecho al reconocimiento de la filiación materna de la casada con la madre gestante», afirma inexplicablemente que el art. 7.3 LTRHA «no altera el principio de unidad de la maternidad que consagra el ordenamiento». Llamemos a las cosas por su nombre: ni la previsión del art. 7.3 LTRHA puede calificarse técnicamente de reconocimiento de filiación, por ser manifiesta y evidente su falta de correspondencia con la realidad ${ }^{8}$, ni cabe negar que nuestro Derecho admite hoy, inexplicablemente, la doble maternidad por naturaleza. Las palabras entrecomilladas de la Dirección General demuestran, patéticamente, cómo legislar contra toda evidencia fáctica y jurídica conduce a una espiral de insensatez sin retorno?.

\section{III.3. La determinación de la paternidad}

Como ya se ha avanzado, la LTRHA no ha introducido un título nuevo, diferente a los recogidos en el Código. Podría haberlo hecho, otorgando la condición de progenitor a quien manifestara su voluntad de serlo y accediera a cualquiera de las prácticas de fecundación asistida de una mujer concreta que la Ley admite con amplitud. Hubiera sido mucho más claro, y hubiera comportado la adición, a los títulos de determinación contemplados en el Código, de uno propio, especial, de la LTRHA. Pero el legislador ha

\footnotetext{
${ }^{6}$ La RDGR (4 $)$ I4 octubre 2009 (JUR 2009\443280) ha aplicado retroactivamente, recurriendo a la analogía con la D.T. I a del Código civil, el art. 7.3 LTRHA, para permitir la determinación de la filiación en favor de la cónyuge de la madre, aun cuando su manifestación de voluntad se hubiera hecho después del nacimiento del hijo, si éste hubiere acaecido antes de la entrada en vigor de la Ley de 2007 . En cambio, si el nacimiento tuvo lugar después de ésta, la RDGR (8) 26 noviembre 2008 (RJ 20I0/459) observa que no puede excluirse el requisito legal de hacer llegar al Registro el consentimiento de la cónyuge de la madre antes del nacimiento del hijo. Doctrina correcta que no aplicó, ante el mismo supuesto, la RDGR $\left(2^{\mathrm{a}}\right) 22$ mayo 2008 (JUR $2009 \backslash 389849$ ), que con farragosa argumentación decide exactamente en sentido contrario: «En el caso presente, la referida reforma del artículo 7 de la Ley $\mathrm{I} 4 / 2006$, llevada a cabo por la Ley 3/2007, hace posible la estimación del recurso aun cuando, en este caso, la declaración haya sido formulada por las interesadas no antes del nacimiento sino con posterioridad al mismo, circunstancia ésta que no puede alterar la finalidad pretendida por la norma». No puede dejar de advertirse que las resoluciones de la Dirección General de Registros solían presentar mayor rigor técnico y cuidado en la argumentación.

${ }^{7}$ Bien expresivas son las palabras de la RDGR 9 de enero de 2002 (RJ 2002\36II): «La maternidad es única en nuestro Derecho y queda determinada por naturaleza. El principio de veracidad biológica que inspira nuestro ordenamiento en materia de filiación se opone frontalmente a que, determinada la maternidad por el hecho del parto, pueda sobrevenir otro reconocimiento de la maternidad por otra mujer». En el mismo sentido la impecablemente fundada RDGR $\left(6^{\mathrm{a}}\right) 5$ junio 2006 , posterior ya a la reforma del matrimonio homosexual y a la LTRHA de 2006.

${ }^{8}$ Lo cual nos situaría ante un reconocimiento nulo, conforme a reiterada doctrina de la Dirección General de los Registros y del Notariado: entre otras, vid. RRDGR 29 enero 200I, 24 enero y 28 diciembre 2002 y 27 abril 2005 .

${ }^{9}$ Y también cómo, partiendo de la sólida argumentación de la RDGR (6 5 junio 2006, la RDGR (4 $)$ I4 octubre 2009 ha practicado un lamentable "corta y pega", tratando de adaptar las declaraciones de la primera a la reforma introducida en el art. 7.3 LTRA.
} 
optado por una manera de proceder más sutil, más complicada, y a la postre más insatisfactoria, porque ha generado muchas lagunas legales.

Más sutilmente, la mediación de técnicas de reproducción asistida requiere la consideración de un nuevo dato, exclusivo para este tipo de fecundación, que no siendo título de atribución de la paternidad, sí es determinante para la filiación del hijo. Este dato viene dado por el consentimiento prestado por el varón para la práctica en la mujer de una determinada fecundación, consentimiento que la LTRHA requiere sea formal, previo y expreso (art. 8.I) a la fecundación «con contribución de donante o donantes» ${ }^{\text {I0 }}$. Ahora bien, dicho consentimiento no atribuye la paternidad: ésta se determina por los cauces habituales, esto es, por los establecidos en el Código civil, en atención a la condición de casada o soltera de la madre. Si es casada, la presunción de paternidad del marido le determina como padre; si no lo es, el medio habitual de atribución de la paternidad es el reconocimiento del padre, que obviamente podrá realizar libremente. ¿Qué añade entonces el expuesto consentimiento previo a la práctica de las TRHA? En el primer caso -filiación matrimonial-, la imposibilidad de impugnar (tanto la mujer como el marido) una filiación que no es conforme con la verdad biológica (art. 8.I); en el segundo -filiación no matrimonial-, la posibilidad de que, a falta de reconocimiento, sirva como escrito indubitado a efectos de determinar la filiación por la vía del expediente gubernativo (art. 8.2 LTRHA) y, si éste deviene contencioso, a través de una acción de reclamación. Que, lógicamente, no será la contemplada en el Código, dirigida a poner de manifiesto la verdad biológica, sino otra distinta, cuya pretensión vendrá basada en dicho consentimiento.

Además, la LTRHA advierte que, en los casos excepcionales en que proceda, la revelación de la identidad del donante en ningún caso implicará determinación legal de la filiación: esto es, el origen biológico del material genético empleado nunca podrá alegarse para determinar la filiación y sus efectos jurídicos (art. 8.3).

Seguidamente, el art. 9 LTRHA contempla la llamada fecundación post mortem: regula los presupuestos bajo los que debe realizarse para que el hijo ostente la filiación del fallecido. Con una notable amplitud, que contrasta con las restricciones presentes en el Derecho comparado, el legislador permite atribuir la paternidad al marido o conviviente con la madre ${ }^{\text {II }}$ no sólo si a su fallecimiento se encontraba el «material reproductor» (art. 9.I) ya implantado en el útero, sino también si el varón (marido o conviviente) hubiera prestado su consentimiento formal para la utilización de su material genético en un plazo de I2 meses posteriores a su fallecimiento. El legislador, además, presume prestado dicho consentimiento cuando antes del fallecimiento del varón se hubiere iniciado sobre la mujer un proceso de transferencia de preembriones ya constituidos (art. 9.2.2).

El tenor literal del art. 9 LTRHA acoge sólo la fecundación post mortem con material genético propio del marido o conviviente fallecido, por lo que quedan fuera los casos de fecundación heteróloga de la mujer. Por consiguiente, ha de entenderse que el consentimiento para esta concreta fecundación sólo produce efectos inter vivos, y que la muerte del varón lo extingue. Con una excepción, la de la presunción contemplada en el art. 9.2.2: aun cuando resulta bastante absurdo extender los efectos de la presunción más allá que los del consentimiento expreso, el tenor de la Ley permite considerar que los preembriones constituidos antes del fallecimiento del varón pueden tener relación biológica con él o no. De manera que en este caso cabe atribuir la paternidad a quien ya ha fallecido y sin que tenga relación biológica con el hijo, nacido con contribución de donante (obviamente, previamente consentida conforme a las reglas generales expuestas) o de una donación de preembrión.

\footnotetext{
${ }^{\text {Io }}$ Aunque el supuesto en que se piensa habitualmente es en el de donación de semen, la contribución puede ser también de gametos femeninos, o de preembriones.

"En realidad, el art. 9.3 dice «varón no unido por vínculo matrimonial»: no hay exigencias legales de convivencia, ni siquiera de relación afectiva equiparable a la matrimonial.
} 
Las reglas especiales sobre determinación de la filiación se cierran, en el art. I0.3, con una norma aplicable a los supuestos de gestación por sustitución: «Queda a salvo la posible acción de reclamación de la paternidad respecto del padre biológico, conforme a las reglas generales». Su sentido no se alcanza sino en relación con la nulidad del contrato de maternidad subrogada, y en contraste con la irrelevancia jurídica de la procedencia del material genético femenino. Si la maternidad viene dada por el parto, la paternidad por el dato biológico, de modo que cabe reclamar la de quien aportó sus gametos para el contrato de maternidad subrogada, «conforme a las reglas generales». ¿También si se contó para ello con un donante, o con la donación de un preembrión? No parece, entonces habrá de tenerse por regla general la del anonimato e imposible determinación de la paternidad. Adviértase cómo la parquedad del legislador obliga continuamente a una difícil interpretación integradora.

\section{Los interrogantes abiertos por la LTRHA}

Expuestas las reglas con las que el legislador ha considerado resuelta la determinación de la filiación nacida a través de técnicas de reproducción humana asistida, pongamos de manifiesto algunos de los importantes interrogantes que su silencio plantea.

\section{IV.I. La impugnación de la paternidad del padre no casado que consiente}

El silencio de la LTRHA en este punto demanda la aplicación analógica del art. 8.I, previsto para el marido. De ahí habremos de extraer una regla contraria a la impugnación de la paternidad por razón de inadecuación biológica cuando se consintió la fecundación heteróloga. Porque de otro modo, la aplicación de las reglas del Código reconducirá la respuesta a la acción de impugnación de la filiación extramatrimonial (art. I40 Cc.), que el Tribunal Supremo también, últimamente, ha considerado aplicable para los supuestos de reconocimiento no conforme con la verdad biológica. Y parece de justicia negar al varón no casado la impugnación que se le niega al marido, en iguales condiciones. Así lo exige, también, la protección de la estabilidad del estado civil del hijo. Pero ha de señalarse la laguna injustificada en que ha incurrido el legislador, para que la supla.

\section{IV.2. La posibilidad de elegir al padre, que no al donante}

Si la mujer está casada con un hombre, la Ley exige, para la práctica de las técnicas de reproducción asistida, el consentimiento de su marido, salvo separación legal o de hecho con constancia fehaciente (art. 6.3). Y ello tanto para la fecundación homóloga como heteróloga.

Si la mujer no está casada, la Ley admite que se someta a dichas prácticas, lógicamente sin consentimiento adicional alguno, aunque conviva con un varón. Lo cual es lógico y razonable, y no puede aducirse seriamente que por ello incurra la Ley en discriminación, por el juego de la presunción de paternidad, que no existe en caso de parejas de hecho. En este caso, el hijo habido por la mujer sólo verá determinada legalmente su maternidad. Como ya he señalado, el art. 8.2 LTRHA sólo contempla el consentimiento del «varón no casado» para la fecundación con contribución de donante, que permite la determinación por la vía del expediente del Registro Civil.

¿Significa eso que una pareja de hecho no puede recurrir a fecundación asistida homóloga, esto es, con gametos procedentes del varón? De ninguna manera: de nuevo, el legislador ha dejado una laguna legal que, en este caso, entiendo de fácil resolución. El varón prestará en tal caso su consentimiento previo a la práctica de la reproducción asistida, 
que servirá, en caso de que tras el nacimiento no practique el reconocimiento, como escrito indubitado a efectos del expediente ante el Registro civil a que se refiere el art. I20.2 Cc. y desarrollan los arts. 47 a 49 L.R.C. Y quedará además a salvo la acción de reclamación de la filiación, cuyo petitum sí se dirigirá en este caso a la prueba de la verdad biológica: en este caso, el consentimiento y el dato biológico coinciden. La impugnación de esta filiación, por otra parte, no resulta problemática, dada dicha coincidencia: no es necesario recurrir a la aplicación analógica del art. 8.I LTRHA.

Ahora bien, dado que la Ley admite como usuaria a la mujer sola, y sólo prohíbe la elección de «donante de semen» (art. 6.4 LTRHA), no hay impedimento legal alguno para que la mujer elija Al "progenitor", entendido éste como padre con efectos legales. Esto es, la Ley sólo admite el nacimiento de hijos sin padre procedentes de donante anónimo. Quien se identifica ante una clínica de reproducción asistida y consiente en la fecundación de una mujer determinada con su semen no es un donante anónimo, sino un progenitor: alguien a quien podrá imputarse, y quien tendrá derecho a asumir, la paternidad con todos los efectos legales $^{\text {12 }}$. De manera que el legislador, al no contemplar que el conviviente consienta la fecundación homóloga de la mujer, no está excluyendo dicha posibilidad: antes bien, está admitiendo que lo haga cualquier varón y no sólo el conviviente, pero con asunción entonces de las responsabilidades parentales, de las que sólo se exime al donante anónimo.

\section{IV.3. La situación jurídica del donante}

El tercer y último párrafo del art. 8 LTRHA trata de extraer al donante del ámbito de la filiación, explicitando que la revelación de su identidad en los supuestos excepcionales contemplados en el art. 5.5 «no implica en ningún caso determinación legal de la filiación». Ahora bien, ¿qué significado ha de darse a dicha expresión? Es obvio, con un mínimo conocimiento de los cauces jurídicos de determinación de la paternidad, que la revelación de la identidad del donante prevista en el art. 5.5 de la Ley, esto es, comunicada por la clínica que practicó la fecundación, no constituye título alguno de determinación de la filiación. Entonces, ¿quiso decir el legislador: «no podrá determinarse la filiación respecto del donante cuya identidad, excepcionalmente, se haya revelado?». Ello supondría una prohibición legal a cualquier cauce de determinación de la filiación en favor (o en contra, según se mire) del donante, tanto judicial como extrajudicial ${ }^{13}$. Prohibición que podría considerarse jurídicamente admisible cuando el hijo tuviera ya determinada una filiación paterna, pero no tanto cuando careciera de ella, bien ab initio, bien por haber sido ulteriormente impugnada con éxito (fecundación de mujer no casada, o de mujer casada con contribución de donante anónimo sin consentimiento del marido). En esta situación: ¿la redacción del mencionado precepto justificaría también la negativa al reconocimiento del donante? En la hipótesis de que éste contara con la aquiescencia de la madre, dado que el art. 7.2 LTRHA prohíbe cualquier constancia registral «del carácter de la generación», no hay medio ninguno para impedirlo. De modo que dicha supuesta previsión legal sería papel mojado. A falta del asentimiento de la madre, la eficacia del reconocimiento dependerá de la aprobación judicial, suscitándose ante el juez la alternativa de aplicar la filosofía de la LTRHA (que no una norma expresa contenida en ella) y dejar al hijo sin un padre existente,

\footnotetext{
${ }^{12}$ En contra NANClARES VALLE, quien considera que la LTRHA sólo permite la fecundación heteróloga en casos de parejas de hecho, en lo que entiendo una interpretación forzada de la Ley: vid. "Las técnicas de reproducción asistida en España: aspectos problemáticos de la Ley de 26 de mayo de 2006 n.I4, con relación a la Ley italiana de ig de febrero de 2004 n. 40", Il Diritto di Famiglia e delle Persone, 2007.2, p. 869.

${ }^{13}$ Así, Verdera SERVER advierte: «En verdad, la norma dice menos de lo que querría decir. (...) Lo que en realidad quería decir el art. 8.3 LTRHA es (...) que el conocimiento de la identidad del donante, esto es, el origen del material genético que ha propiciado la fecundación no permite articular una pretensión, judicial o extrajudicial, tendente al establecimiento de una filiación conforme con esa aportación de material genético», loc. cit., p. 253.
} 
o ratificar un reconocimiento veraz. Como siempre, las leyes torpes trasladan los problemas a los jueces, cuya función no es crear normas, sino aplicarlas.

De manera que no sólo el tenor literal de la norma, sino también la supuesta voluntas legislatoris resultan problemáticas por absurdas. Y es fácil descubrir el porqué: el art. 8.3 LTRHA se apoya y es consecuencia del art. 5.5, que consagra el anonimato del donante, verdadero principio inspirador y leiv motiv de la Ley ${ }^{\mathrm{T}}$. Y la inconsistencia e injusticia implícita en éste se comunica a cuanto de él trae causa. Aunque el Tribunal Constitucional, ratificando su constitucionalidad, tratara de "salvarle la cara" al legislador. Efectivamente, la STC iı6/ı999, de I7 de junio, justificó tal declaración sobre la admisible separación entre la filiación legal y la biológica. El recurso alegaba que la inconstitucionalidad del anonimato era contraria a la investigación de la paternidad, y se desestimó al observar que tal principio no es absoluto, y puede excepcionarse justificadamente, como en este caso, en que tal revelación no se ordena al establecimiento de la relación legal paterno-filial, sino sólo a la identificación del donante de los gametos ${ }^{15}$. La argumentación es endeble, y hace supuesto de la cuestión, al dar por hecho la imposibilidad de determinar la relación paterno-filial: como digo, echa una mano al legislador, dando por supuesta la declaración que no hace, pero no convence. Por muchísimas razones, pero sobre todo por una: si la Ley se hubiera asegurado de que todo nacido a través de TRHA tuviera un padre legal, el argumento del Tribunal Constitucional podría sostenerse: el anonimato se funda en lo innecesario de señalar un sujeto a quien la Ley no va a admitir como padre legal, porque ya hay uno señalado como tal. Pero la propia Ley posibilita el nacimiento de hijos sin padre, situación ante la que el anonimato del donante sólo resulta reveladora de una verdad incontrovertible: la LTRHA ha desatendido sistemáticamente los derechos del hijo nacido a través de estas técnicas. El legislador ha considerado los intereses de quienes desean ser padres, los de las clínicas que prestan estos servicios, los de quienes procuran material genético que los haga posibles, pero no ha contemplado en absoluto al hijo como sujeto, como persona digna y merecedora de protección, sino sólo como objeto de deseo.

Y frente a él, la supuesta «inmunidad jurídico-familiar» del donante de semen carece absolutamente de razón de ser, dada la evidente diferente entidad de los bienes jurídicos en liza ${ }^{\mathrm{T} 6}$. Como las evidencias terminan por imponerse, el reconocimiento del derecho a conocer el propio origen va abriéndose camino en los ordenamientos jurídicos

\footnotetext{
${ }^{14}$ Sobre este punto, no me resisto a enviar al lector interesado a un trabajo que puede calificarse ya de clásico, cuyas afirmaciones siguen plenamente vigentes, dado el superficial afrontamiento que un tema jurídico tan relevante mereció del Tribunal Constitucional: PANTALeón PRIETO, «Contra la Ley sobre técnicas de reproducción asistida», en Homenaje al profesor Juan Roca Juan, Universidad de Murcia, I989, pp. 662-670.

${ }^{15}$ STC ir6/1999, de I7 de junio: «La Constitución ordena al legislador que posibilite la investigación de la paternidad, lo que no significa la existencia de un derecho incondicionado de los ciudadanos que tenga por objeto la averiguación, en todo caso y al margen de la concurrencia de causas justificativas que la desaconsejen, de la identidad de su progenitor. Pues bien, desde esta perspectiva, la Ley enjuiciada sólo podrá ser tachada de inconstitucional, por infringir lo dispuesto en el art. 39.2 C.E., en la hipótesis de impedir, sin razón o justificación alguna, la investigación de la paternidad. No es éste el caso de la previsión contenida en el art. 5.5 de la Ley 35/I988, que garantiza la no revelación, como regla, de la identidad de los donantes de gametos. Conviene no olvidar, como base de partida, que la acción de reclamación o de investigación de la paternidad se orienta a constituir, entre los sujetos afectados, un vínculo jurídico comprensivo de derechos y obligaciones recíprocos, integrante de la denominada relación paterno-filial, siendo así que la revelación de la identidad de quien es progenitor a través de las técnicas de procreación artificial no se ordena en modo alguno a la constitución de tal vínculo jurídico, sino a una mera determinación identificativa del sujeto donante de los gametos origen de la generación, lo que sitúa la eventual reclamación, con este concreto y limitado alcance, en un ámbito distinto al de la acción investigadora que trae causa de lo dispuesto en el último inciso del art. 39.2 de la Constitución.»

${ }^{16}$ Rivero HernándeZ observa que aunque el Tribunal Constitucional estimó el anonimato conforme con el art. 39.2 CE, también contraría los arts. IO.I, I4, I5, I8 CE y el principio de proporcionalidad: vid. "La constitucionalidad del anonimato del donante de gametos y el derecho de la persona al conocimiento de su origen biológico", Revista Jurídica de Cataluña, 2004.I, pp. I05-I34.
} 
modernos, tanto para los hijos adoptivos, como para los nacidos de reproducción asistida ${ }^{\mathrm{r}}$. Propiciado no sólo por el desarrollo en el contenido de los derechos fundamentales, sino también por instancias internacionales como el Comité de los Derechos del Niño de la ONU, que advierte de la posible contradicción del anonimato del donante con los arts. 3 y 7 del Convenio sobre Derechos de los Niños ${ }^{\mathrm{r}}$. Pues bien, si la tendencia legislativa conduce a la desaparición del anonimato, ¿comportará también la derogación de la imposibilidad de determinar la paternidad del donante? No necesariamente: podrá ahondar en la separación entre la filiación natural o biológica y la legal, senda por la que la aplicación del principio de verdad biológica ha conducido a la filiación por naturaleza ${ }^{\text {19. }}$. Así, la identificación del «progenitor biológico» puede no convertirlo en padre legal, sino quedarse en una mera declaración sin efecto jurídico alguno. Lo cual, insisto en una idea ya expuesta, puede resultar plausible en presencia de un padre legal, pero no tanto si éste falta. Se podrá argumentar que la filiación debe desvincularse de las instituciones protectoras de menores. Pero por ese camino, el legislador deberá ser extraordinariamente cuidadoso, para no arrumbar un principio de responsabilidad de los progenitores hacia sus hijos que ha costado siglos incorporar a los ordenamientos jurídicos.

Como poco, es indudable que la desaparición del anonimato hará más conscientes a los donantes de la trascendencia de su acto.

\section{IV.4. Los derechos del hijo nacido mediante TRHA}

El análisis del punto anterior nos ha situado ante el silencio clamoroso que en cuanto al hijo se refiere mantiene la LTRHA, que además de manifestar la filosofía que la anima, constituye fuente de multitud de interrogantes. Silencio que contrasta con el papel protagonista que el Código civil otorga al hijo en la regulación de la filiación, y que en lo relativo a su determinación, se concreta en la amplia legitimación que se le reconoce para el ejercicio de las acciones de reclamación e impugnación. Si, según ha quedado expuesto, la Ley parte de la aplicación del Código «a salvo de las especificaciones establecidas en los tres siguientes artículos» (art. 7.I LTRHA), han de entenderse aplicables las previsiones de aquél en cuanto al hijo. Por consiguiente:

a) Podrá ejercitar las acciones de impugnación de la paternidad contra quien por consentir se convirtió en padre por su sola voluntad: recuérdese que la Ley sólo niega legitimación a tales efectos a la «mujer progenitora y al marido», en declaración que hemos debido entender aplicable en general al varón que consiente (art. 8.I LTRHA). Ni siquiera la interpretación del art. 8.3 más afín a los propósitos de la Ley puede alegarse para negar dicha legitimación ${ }^{20}$. Y aún con mayor razón podrá impugnar la doble maternidad de la cónyuge de quien le dio a luz. ¿Puede seriamente oponerse al ejercicio de una acción impugnatoria una declaración de voluntad manifiestamente incierta?

b) La posible legitimación del hijo para reclamar la paternidad al donante nos sitúa ante el mismo problema mencionado en el subepígrafe anterior, que resulta aún más

${ }^{17}$ Suiza, Suecia, Austria, Holanda, Reino Unido, Noruega y Finlandia han reformado sus legislaciones sobre reproducción asistida, para reconocer al hijo el derecho al conocimiento de la identidad del donante: vid. GARRIGA GoRINA, «El conocimiento de los orígenes genéticos en la filiación por reproducción asistida con gametos donados por un tercero», Derecho Privado y Constitución, nº 2I, 2007, p. I97.

${ }^{18}$ Vid. GARRIGA GoRINA, loc. cit., p. 202, donde cita diversos informes de dicho Comité sobre legislaciones europeas.

I9 Al respecto, vid. BARber CÁRCAmo, «Nuevos retos ante el Derecho español de filiación», R.D.P., julioagosto 2009 , pp. 45-47.

${ }^{20}$ Acerca de la controversia doctrinal existente sobre este tema, vid. NANCLARES VALLE, «Las técnicas de reproducción asistida en España...», cit., p. 877 n. 57. 
evidente desde la perspectiva de aquél, sobre el que no insistiré. Sólo advertir que cabe una interpretación analógica de lo dispuesto para los hijos adoptivos, quienes pueden ejercitar la acción para la determinación de su filiación biológica sin incidencia alguna sobre la adopción (art. I80.4 Cc.). Que sería respetuosa, además, con la previsión contenida en el art. 8.3 LTRHA.

\section{Conclusión: valoración de la Ley 14/2006, de 26 de mayo, de Técnicas de Reproducción Humana Asistida}

Cuanto ha quedado expuesto justifica calificar esta Ley, desde consideraciones de estricta técnica jurídica, sin entrar en las filosóficas, como: a) contradictoria, por prever su integración con las normas civiles generales, basadas en el principio de verdad biológica, sistemáticamente desatendido en ella; b) falta de técnica, por desconocer el funcionamiento propio de los títulos de determinación de la filiación; c) insuficiente, por sus clamorosos silencios, que obligan a una difícil labor interpretativa; d) voluntarista, por tratar de imponer la voluntad sobre la realidad misma (doble maternidad por naturaleza); y e) imprudente, por permitir el nacimiento de hijos sin padre (fecundación post mortem, de mujer sola) y, en general, desatender cualquier consideración sobre el interés del hijo más allá de su propio nacimiento, focalizando exclusivamente la regulación sobre los intereses de los usuarios de las técnicas y las clínicas que brindan su aplicación.

Una rápida consulta en Internet puede ofrecer una cumplida idea sobre los resultados prácticos de la aplicación de esta Ley. Ofreceré sólo dos ejemplos, bien ilustrativos, que el lector puede incrementar. Uno: bajo la denominación «maternidad compartida», las clínicas ofrecen una nueva técnica de fecundación in Vitro a los matrimonios de lesbianas, denominada ROPA (Recepción de Óvulos de la Pareja). Consiste en la fecundación de los óvulos de una de ellas con esperma de donante anónimo, para su implantación en el útero de la otra. Según se explica en una web: «De esta forma ambas participan en la gestación, ambas han de dar su consentimiento informado y ambas tendrán derechos y obligaciones sobre el niño» ${ }^{2 \mathrm{I}}$. Afirmaciones repugnantes para cualquier jurista, porque no hay peor mentira que una media verdad. Ambas no participan en la gestación: sólo hay una madre gestante y con los derechos propios de quien pare; los consentimientos informados se referirán a objetos bien diversos: la donación de óvulo, en un caso, y el sometimiento a las técnicas de fecundación, en otro; y los derechos y obligaciones sobre el niño dependerán de la exclusiva voluntad de la madre no gestante, a quien no hay medios legales para imponer la declaración del art. 7.3 LTRA. Obsérvese además cómo se desatiende la exigencia legal del anonimato en la donación de gametos (masculinos y femeninos, no se olvide), con apoyo en el art. II.4 a) LTRHA, que permite la utilización del material genético «por la propia mujer o su cónyuge». La Ley ha permitido que la fecundación asistida no sea ya un remedio a la esterilidad, como en la Ley 35/1988, de 22 de noviembre (art. I.2) $)^{22}$, abriendo puertas cerradas en la mayoría de los ordenamientos de nuestro entorno.

\footnotetext{
${ }^{21}$ http://www.institutocefer.com: «Maternidad compartida: Niño con dos madres biológicas. Ropa : Una nueva indicación de FIV. Barcelona, a 8 de Enero 20IO. En España, desde que funciona el primer banco de semen el I4 de Enero de I978, se ha podido tratar a mujeres lesbianas con semen de donante anónimo para tener hijos. La ley i3/2005 y la ley I4/2006 equiparan los derechos de la pareja lesbiana con los de la pareja heterosexual. Ello permite que una mujer aporte los óvulos, éstos sean fecundados con semen de banco y los embriones se transfieran al útero de su pareja. De esta forma ambas participan en la gestación, ambas han de dar su consentimiento informado y ambas tendrán derechos y obligaciones sobre el niño». La noticia continúa ofreciendo, con notorias imprecisiones, datos sobre la situación de las uniones homosexuales en el Derecho comparado. Y curiosamente, menciona que la técnica descrita se aplica en España desde febrero de 2007, esto es, con anterioridad a la reforma de la LTRHA de I5 de marzo del mismo año, que incluyó el art. 7.3.

${ }^{22}$ Previsión que seguía conteniendo el proyecto de la vigente LTRHA, art. I.I.a) («Regular la aplicación de las técnicas de reproducción humana asistida científicamente y clínicamente indicadas, para facilitar la procreación
} 
Otra posibilidad ofrecida por algunas clínicas es la inseminación de las dos mujeres de una pareja homosexual con semen del mismo donante, bien consecutiva, bien simultáneamente. Lo cual, ciertamente, puede calificarse de conforme con la literalidad de la Ley, pero relativiza el anonimato de las donaciones, así como la prohibición de la elección del donante.

En suma, la legislación española sobre reproducción asistida se ha dictado al margen del hijo como sujeto principal digno de protección, lo que está determinando su aplicación y desarrollo. Presenta el muy dudoso honor de posibilitar prácticas prohibidas en otras legislaciones de nuestro entorno. Por ello, y desde muy diversos flancos, ha de defenderse su derogación y sustitución por otra Ley que, siguiendo las más modernas tendencias del Derecho comparado, otorgue al hijo nacido el papel rector que como persona a proteger le corresponde. Intereses del hijo que, en muchos casos, justifican la negativa a la práctica de la reproducción asistida ${ }^{23}$.

en casos de esterilidad»), y desapareció tras su discusión parlamentaria. Vid. Serna Meroño, "Comentario al artículo 6", en Совасно Gómez (dir.), Comentarios a la Ley 14/2006, de 26 de mayo, sobre Técnicas de Reproducción Humana Asistida, Cizur Menor, Thomson-Aranzadi, 2007, pp. I83 ss.

${ }^{23}$ Así, la STEDH (sección 4a) I8 abril 2006 (Dickson contra Reino Unido) (TEDH 2006\3I) consideró inexistente la vulneración del derecho a la vida familiar por negar el acceso a técnicas de reproducción asistida a un condenado por asesinato, con fundamento en la confianza en el sistema penitenciario y el bienestar del hijo, que carecería de recursos materiales y de figura paterna en un período prolongado de su infancia. 